\title{
Currículos e redes: o calar, o silêncio, outros espaços
}

\author{
e o canto das sereias
}

\section{Curriculums and networks: the quiet, the silence, other spaces and the siren song}

\author{
Currículos y redes: el callar, el silencio, otros espacios \\ y el canto de las sirenas
}

\author{
Alexandre Luiz Polizel \\ Universidade Estadual de Londrina (UEL), Londrina/PR - Brasil
}

\begin{abstract}
Resumo
Este manuscrito tem por objetivo levantar considerações acerca dos movimentos sociais, da instituição currículo e das redes sociais. O trabalho se apresenta sob os moldes de um ensaio teórico, influenciado pelos referenciais teóricos de Michel Foucault (2007; 2014a; 2014b; 2015; 2016) e dos estudos culturais. O texto se encontra organizado em três eixos: a) a instrumentalização sobre currículos, movimentos sociais e os aportes foucaultianos sobre saberpoder-verdade; b) a lógica neoliberal implementada nos currículos, que incita a competição, a rivalização e o fazer calar frente as críticas sobre a verdade; e c) o esvaziamento do espaço escolar e as redes sociais como espaço de potência. $\mathrm{O}$ artigo se enreda com as ideias do calar pelas atuais milícias da sociedade de controle e com o silêncio como espaço de criação e de possibilidades, sob influência de Jorge Larrosa (2001). As considerações elencadas no trabalho servem mais como provocações, trazendo ao centro a discussão sobre as potencialidades das redes sociais e os engessamentos curriculares, convidando outros a falarem sobre tais temáticas.
\end{abstract}

Palavras-chave: Estudos culturais, Currículos, Redes, Ensaio

\begin{abstract}
This manuscript aims to raise considerations about social movements, curriculum and social networks. The work is a theoretical essay, influenced by the theoretical frameworks of Michel Foucault (2007; 2014a; 2014b; 2015; 2016) and Cultural Studies. The text is organized in three axes: a) instrumentalization on curricula, social movements and Foucault's contributions on know-power-truth; b) the neoliberal logic implemented in the curricula, which encourages competition, rivalry and silence before criticism about Truth; and c) the emptying of school space and social networks as a space of power. The text entangles the ideas of silence by the control society current militias and with silence as a space of creation and possibilities, under the influence of Jorge Larrosa (2001). The considerations listed in the work function as provocations, focusing the discussion about the social network potential and the curricular plaster, inviting others to talk about such themes.
\end{abstract}

Keywords: Cultural studies; Curricula; Networks; Essay 


\section{Resumen}

Este manuscrito tiene como objetivo plantear consideraciones sobre los movimientos sociales, la institución curricular y las redes sociales. El trabajo se presenta en forma de ensayo teórico, influenciado por los marcos teóricos de Michel Foucault (2007; 2014a; 2014b; 2015; 2016) y de los estudios culturales. El trabajo está organizado en tres ejes: a) la instrumentalización sobre currículos, movimientos sociales y aportes de Foucault sobre saber-poderverdad; b) la lógica neoliberal implementada en los planes de estudio, que fomenta la competencia, la rivalidad y el silencio frente a las críticas a la verdad; $y, c)$ el vaciamiento del espacio escolar y las redes sociales como espacio de poder. El texto se enreda con las ideas del silencio de las milicias actuales de la sociedad de control y con el silencio, como espacio de creación y posibilidades, bajo la influencia de Jorge Larrosa (2001). Las consideraciones enumeradas en el trabajo sirven más como provocaciones, llevando al centro la discusión sobre las potencialidades de las redes sociales y el yeso curricular, invitando a otros a hablar sobre tales temas.

Palabras claves: Estudios culturales, Currículos, Redes, Prueba

\section{O início das dissonâncias}

Este trabalho foi construído nas relações decorrentes das imbricações entre os currículos, movimentos neoliberais e dos cantos sirênicos. Entretanto, como pensar nos sons em uma escrita? Acreditamos que é pensando nos efeitos deste manuscrito sobre aqueles que virão a interagir com ele. Deixaremos a responsabilidade da decisão sobre a consonância ou a dissonância deste texto aos leitores e a suas potencialidades. Para iniciar as reflexões levantadas neste ensaio, apresento três personagens que nos modalizarão em tais problematizações: os discursos neoliberais, currículos e os cantos sirênicos. Mas o que teriam em relação esses três discursos?

Para conferir esses fenômenos, iniciamos o trabalho com o personagem Harry Potter abrindo o ovo do dragão e se deparando com uma insuportável algaravia de sons estridentes, que o força a recuar e procurar novas estratégias e aliados para dar conta das tarefas a ele designadas.

A cena faz parte do filme Harry Potter e o cálice de fogo, [baseado no livro] escrito pela inglesa Joanne Jo Rowling (2000), roteirizado por Steven Kloves, produzido pela empresa Warner Bros, em 2005, e dirigido por Mike Newell.

A cena começa com Harry Potter, personagem central da trama, obrigado a participar do Torneio Tribruxo, que consiste em um campeonato entre bruxos de três escolas diferentes, passando por três desafios: desafio 
dos dragões, desafio do lago e desafio do labirinto. O desafio dos dragões consiste em utilizar de sua audácia e coragem para coletar um ovo de ouro no ninho dos dragões. Esse ovo continha uma dica sobre a próxima tarefa. Após Harry coletar o ovo, ele é carregado por seus amigos, que comemoram a primeira missão cumprida e clamam pela abertura do ovo, para vislumbrar o que viria pela frente. Ao abrir, a dissonância dos sons que saem do ovo faz com que todos tapem os ouvidos. Contudo, após sugestões do jovem Cedrico e da fantasma Murta-Que-Geme e da abertura do ovo embaixo d'água em uma banheira, Harry ouve uma bela melodia e afirma: "Sereianos". Essa informação Ihe possibilita preparar-se para o desafio do lago.

Ao chegar na prova do lago, Harry se depara com vários "Sereianos", os mesmos que cantavam a bela melodia, e os colegas dos competidores amarrados ao fundo do lago pelo pé, em uma corda. Harry pensa em levar mais de uma pessoa, mas é advertido pelos Sereianos que apenas um poderá ser levado por cada competidor. Harry desafia as regras e liberta duas pessoas. Ao descumprir as regras, Harry é atacado por vários Sereianos, que agem como uma milícia, os guardiões da regra, que vigiam e punem aqueles que quebram as normativas.

Nosso interesse nesse texto não se refere propriamente às míticas das Sereias e Sereianos, mas, sim, às performances que fazem. Sedutoras e monstruosas, esses seres mitológicos possuem a potencialidade para cantar as mais lindas canções, que fascinam, encantam e agenciam os desejos e as potencialidades, ao mesmo tempo em que atuam como uma milícia guardiã das normas. O estranhamento, a incompatibilidade, a incompreensão são motores agenciando nossos personagens em direção à (des)ordem.

É nas performances das Sereias e Sereianos, que vemos os estudantes contemporâneos fazerem ecoar suas vozes, seus encantos e seus desejos de potência, silenciarem-se como um espaço de produção de sentidos, espaço de agenciamentos, de milícia. Fiscais vigilantes. Tomando essa linha de reflexão, o presente ensaio tem por objetivo levantar considerações acerca da educação, traçando paralelos sobre Sereias, Sereianos, o currículo e o neoliberalismo, como um instrumento entremeado de políticas do calar e do silêncio. Organizamos este ensaio teórico em três partes: a) Abrindo o ovo; b) 
movimentos neoliberais e a sociedade disciplinar; c) $\mathrm{O}$ esvaziamento da escola, as Sereias e as redes sociais como espaços de potencialidade.

\section{Abrindo o ovo}

Para ouvir o canto dos Sereianos, Harry foi aconselhado a submergir o ovo na água. Quando o ovo estava imerso em seu espaço idiossincrático, os sons produziram significados compreensíveis e plausíveis ao ator externo que se propôs à imersão, a levar a sério o lócus da produção. Ouvir dissidências e consonâncias exige exposição, exige a nudez nômade do desejo, da humildade frente à diferença, tanto quanto exige, para dizer nos termos de Foucault (2016), de "ferramentas" de escuta. Tal instrumental são as lentes pelas quais olhamos a literatura como um espaço do narrar e do ouvir, ou seja, como conceituo o que trato enquanto currículo e o que trato como movimentos sociais.

A inspiração deste trabalho provém da perspectiva dos estudos culturais, ou seja, consideram-se os conhecimentos como relações de poder, espaços de lutas em torno de processos de significação social, que geram efeitos sobre os possíveis modus de existência (SILVA, 2015), isto é, uma imersão no mundano e nos jogos de poder. É nesse viés teórico, que nos inclinamos a examinar práticas culturais do ponto de vista de seu envolvimento, no interior das relações de poder e de linguagem (NELSON; TREICHLER; GRASSBERG, 2013).

As relações de poder serão tratadas aqui na perspectiva foucaultiana (FOUCAULT, 2016; 2015; 2014a; 2014b; 2007; YAZBEK, 2015), de modo a assumir que o poder não possui essência ou posse de um aparato estatal, mas é constituído em processos sociais históricos, pulverizado, capilarizado, produtivo, microfísico e tramado com o saber. Saber, para Foucault (2016; 2014b; 2007), consiste em um grupo coordenado de enunciados e de funções enunciativas que o instituem como verdade. Esses saberes-poderes-verdades sofrem transformações de tempos em tempos, modificando suas configurações e produzindo novos efeitos discursivos. Dessa forma, para um saber-poder surgir, ele necessita de condições específicas, que possibilitam seu emergir e sua permanência, passando de enunciação para enunciado, por meio de reiterações e rarefações. 
Esses jogos enunciativos que se estabelecem e produzem regimes de verdade passam então a legitimar o que é certo ou errado, bom ou mal, normalizado ou desviado, natural ou anormal (FOUCAULT, 2016; 2015; 2014a; 2014b; 2007; YAZBEK, 2015). É nesse ponto que os regimes de verdade naturalizam coisas não naturais e passam a reger e governar corpos e mentes. Assim, manter verdades em circulação passa a ser função das múltiplas instituições sociais, e a escola tem papel central na produção de corpos produtivos e mentes docilizadas (FOUCAULT, 2015; 2014a), sendo o currículo um útil artefato cultural que o mantém em movimento.

O currículo, como artefato cultural, atua, analisando, organizando, triando e elegendo quais saberes são formativos ou não, para que possam se constituir como verdade (POLIZEL; CARVALHO, 2016; SILVA, 2015; GOODSON, 2008) e se manterem em circulação. Essa autenticação da validade do saber é dada por: a) artífices da cientificidade das coisas; e b) pela sua instituição nos sistemas escolares de currículo e políticas públicas.

Os artífices da cientificidade das coisas investem na produção de enunciado, na elaboração de saberes; as instituições, no processo de transposição didática, ensino e validação de tais saberes enquanto formativos. Essa interlocução artífices-instituição coloca as discursividades de encontro aos corpos, aos sujeitos, aos estudantes, que, nessa relação, negociam com as elas e constituem a si a partir delas.

É na constituição do eu, por via dos regimes de verdade, que as ações de si são reguladas, de modo que, ao se conhecer a verdade, deve-se agir por ela. $O$ agir, mesmo que sozinho, parte do ideal do agir na verdade, resultado dos sistemas regulatórios provindos do saber escolarizado (FAVACHO, 2016). É evidente que não são apenas os saberes escolares que regulam os modos de ser, mas apresenta um fortalecimento discursivo, por carregar consigo a ideia mátria de validade, atravessada pelo crivo da cientificidade moderna.

Desse modo, a eleição de saberes se encontra conectada com a eleição dos modos de ser, e esse processo não ocorre de maneira orgânica, pacífica, homogênea e consensual, mas, sim, em campos de guerra. Campos onde são travadas lutas entre os movimentos sociais, representantes do legislativo, membros da sociedade civil organizada e dos portadores do discurso especializado nas questões de ensino. É no território de contestação, que os 
movimentos sociais atuam para garantir a manutenção da consciência de si (ARROYO, 2015) ou do governo de si e dos outros.

Tais governamentos ${ }^{1}$ - de si e dos outros - são colocados em operação e efetivados ou não, a partir do esforço dos movimentos dos atores sociais que se encontram na tração de forças, para que tais curricularidades sejam efetivadas. Esses movimentos sociais consistem/ se constituem em um emaranhado de indivíduos, que se associam e organizam coletivamente, de acordo com interesses e necessidades sociais e políticas. Esses movimentos podem encontrar-se interligados à aquisição de direitos e/ou a sua manutenção. Organizo-os em duas esferas: a) movimentos sociais minoritários, que buscam a ampliação da liberdade e o afrouxamento das condições de assujeitamento $^{2}$ e b) movimentos sociais (neo)fundamentalistas, que têm por vontade a manutenção do status quo.

Ambos os movimentos têm sido atravessados por políticas neoliberais na contemporaneidade. Aqui, não queremos universalizar a ideia de neoliberalismo, mas, sim, considerá-lo uma tecnologia de governo e governamento da vida, que instiga a competição, disputa e rivalização. São esses instrumentais que nos permitem abrir os ovos. Contudo, como Harry, precisamos submergir o ovo na água, para podermos ouvir ou não o que os Sereianos nos dizem.

\section{Movimentos neoliberais e a sociedade disciplinar}

É pela submersão ao mundo que ouvimos o canto. O canto nos coloca a pensar nas políticas do fazer calar e do silêncio. Larossa (2001) traz belamente essa dança do calar e do silêncio. O calar seria o mundo desprovido de vida, a rotina, as monotonias, tudo o que cristaliza e impede outras formas de pensar, o que cerceia e bloqueia os fluxos de potência limpando os ruídos. O silêncio seria um mundo aberto a descobertas, às potencialidades, ao (re)inventar-se, (re)encontrar-se, traduzir ruídos em música. No silêncio, se contempla; no calar, é-se obrigado a interpretar as sensações de forma única.

\footnotetext{
${ }^{1}$ Compreendemos governamentos juntamente a Michel Foucault (2016), enquanto modos de organizar, regular e exercer poder sobre os corpos dos sujeitos e populações.

2Para Branco (2015,) o assujeitamento consiste no exercício de controle da subjetividade que constitui a própria individualidade.
} 
Os espaços educativos, a escrita, os filmes, as novelas, as artes e os currículos podem ser espaços de calar ou espaços de silêncio. No entanto, como os currículos se relacionarão com o calar ou silenciar das Sereias? Como o espaço escola seria um espaço no qual as Sereias e Sereianos se silenciam ou são calados e se tornam milícias das normas? Acreditamos que a chave entre currículos e o fazer calar se encontra relacionada à noção de verdade.

Os currículos, dentre eles os Currículos (com C maiúsculo), estão intrinsicamente fechados, cristalizados e essencializados, em sua noção de verdades. Currículos produzidos nas tramas das relações de poder elegem o que é formativo ou não, o que é valido de ser instaurado como verdade ou não, regendo a maneira que se pode cantar (SILVA, 2015; 2001). Quando apenas uma verdade pode ser veiculada, existe apenas um modo de falar; o poder atua fazendo o outro se calar, ficar confuso, mudo, repetir e ter a incapacidade da palavra. A força do calar é evidenciada quando o poder é o único que fala (LARROSA, 2001).

Esse poder, vinculado nos currículos, é a autoridade da racionalidade neoliberal $^{3}$ (SILVA, 2015; 2001), o poder autoritário no qual a razão se classifica como único saber válido, detentor de "a" verdade. O currículo se instaura então como uma máquina de planejar quais verdades e de que forma serão 'apresentadas' no espaço escola. Ao final, as Sereias e os Sereianos serão avaliados: se cantam na cartilha do verdadeiro ou se passarão mais um ano pelo curso (VEIGA-NETO, 2012).

Michel Foucault (2016; 2015; 2014a; 2014b; 2007; YAZBEK, 2015), ao pensar em verdades, pontua que elas são constituídas em grupos, sob condições específicas, que possibilitam a enunciação em se manterem como enunciado e terem efeitos de verdade.

Vê-se assim que as Sereias e Sereianos são proibidos de tratar de assuntos, como cotidiano, políticas, sexualidades; os mundanos não devem

\footnotetext{
${ }^{3}$ Compreende-se, neste manuscrito, que a racionalidade neoliberal se ancora em um modelo de representação econômica e ideológica, bem como enquanto um modo de compor as racionalidades na contemporaneidade. Ela opera pela destruição de instituições e modos de existir que não operam, ou que obstaculizariam, sua funcionalidade prático-ideológica, bem como produz outras formas de vida, relações sociais e subjetividades. As bases dessa racionalidade neoliberal se centram em uma reinterpretação de noções, como responsabilidade, liberdade e consciência, lançando mão de técnicas e tecnologias para produção de discursividades e subjetividades alinhadas a tal regime de racionalidade (VEIGANETO, 2012; FOUCAULT, 2016; TIBURI, 2016).
} 
compor o escopo do falado em sala. O que as Sereias e os Sereianos podem cantar deve estar dentro do assunto trabalhado naquele momento, naquela circunstância, ou deverá ser falado apenas em momentos pertinentes. $O$ direito privilegiado e exclusivo da fala é destinado ao professor, se ele estiver falando do assunto contemplado no currículo, pois se tem a ideia de que só ele tem autoridade intelectual para isso.

Os interditos não impedem Sereias e Sereianos de pensar determinados discursos, mas os impedem de colocar em circulação o cantar. Apenas cantase o que é eleito verdadeiro, o que não é interditado. O currículo, quando engrenado nos moldes da racionalidade neoliberal, é quase bíblico, portador da verdade única e verdadeira e apenas por essa será salvo. É sob tal ladainha, que as Sereias e os Sereianos são calados, emudecem e passam, não apenas a replicar o Verdadeiro, mas se tornam seus milicianos, assumindo-se como os guardiões da norma que detêm a verdade, catequizando o Outro, vigiando-o e punindo-o.

\section{O esvaziamento da escola, as sereias e as redes sociais como espaços de potencialidade}

Já que nos colocamos a falar de sereias, recorremos à descritiva de duas cenas, que possibilitam um redirecionamento de holofotes aos currículos. Uma cena do filme Harry Potter e o cálice de fogo e a segunda no conto Odisseia, inspirados na leitura de Tiburi (2016).

\section{Cena 1}

Harry Potter, ao ser convocado ao desafio do lago, é informado que, no fundo do lago, existe uma pessoa importante para cada competidor [do Torneio Tribruxo]. Ao chegar no fundo, ele percebe que Fleur [uma das competidoras] havia sido retirada da prova por problemas com os diabos marinhos e cogita a possibilidade de levar também à superfície a irmã de Fleur. Contudo, Harry é advertido por um dos sereianos que apenas uma pessoa pode ser levada. Em um ato de coragem, ele liberta a irmã de Fleur e Ronny [seu amigo] e tenta levá-los a superfície. Nesse caminho, Harry é atacado por inúmeros sereianos, mas consegue se livrar deles e concluir a prova. Seu ato de coragem garanteIhe o segundo lugar no desafio. 


\section{Cena 2}

Imaginemos Ulisses, o herói homérico de Odisseia, em sua cruzada para ouvir as sereias. Ele queria encontrar as sereias, ouvi-las, mas sem enlouquecer e cair em seus feitiços. Então, amarra-se em um mastro com cordas e solicita a toda a tripulação que tape seus ouvidos com cera. As sereias não cantam, se silenciam diante daquele sujeito bobo, cheio de parafernálias para se proteger do seu canto telúrico, que encanta a qualquer um que o ouve. As sereias não cantam, mas Ulisses, como bom herói, não podia relatar que foi capturado pelo silêncio. Ele finge que ouviu e vai embora.

É em um paralelo com essas cenas ficcionais, que podemos levantar análises e diagnósticos do presente, ou, ao menos, buscar aproximações no que toca aos movimentos neoliberais atuais e aos currículos. Quando tratamos aqui de diagnóstico do presente, faço a relação com a perspectiva foucaultiana, na qual são analisadas saber-poder-verdade (BRANCO, 2015).

É à primeira cena, que recorreremos para discutir o cenário neoliberal de produções curriculares, e à segunda, para pensar os vazamentos e erupções da instituição escola.

\section{Sereianos: currículos, regras e heroísmos}

A produção curricular tem um rito de produção, com velas, cânticos e rezas, para agradar o novo Messias, que carrega consigo a verdade. Podemos ver atualmente dois exemplos de rito para a produção curricular: a) Os planos nacionais, estaduais e municipais de educação e b) A nova reforma do ensino médio.

A produção dos Planos de Educação (PE) é delegada por medidas legislativas da Constituição Federal de 1998 e das Leis de Diretrizes e Bases da Educação, implantada em 1996, que afirmam a necessidade de produção dos PEs, de acordo com a Declaração Mundial Sobre a Educação para Todas e Todos, produzida na Conferência de Jomtien, Tailândia, no ano de 1990. Os PEs teriam assim a preocupação com a implementação de metas educacionais que vigorariam na educação por 10 anos.

No Brasil, o último PE foi aprovado em 2014 (com atraso, visto que regeria 2011-2020, o que levou a estender para 2014-2024), em meio a embates políticos e ideológicos. Embora o PE devesse prezar a equidade e 
igualdade de direitos e deveres educacionais para a população, ele foi deturpado, em meio à pressão de bancadas religiosas e neofundamentalistas ${ }^{4}$, que tratam como ameaça as palavras gênero, etnia/raça, diversidade sexual e regionalidade, por estarem presentes no texto (CARVALHO et al., 2015). A pressão das frentes neofundamentalistas atravancou a aprovação do projeto com "Gênero não", como o Sereiano, que dizia as regras a Harry nas condições de "Apenas um". Eram regras no rito, que queriam tornar-se regras nos currículos.

Foi um território de guerra, no qual movimentos sociais minoritários e as instituições de educação e pesquisa se digladiaram frente aos movimentos político-religiosos. De um lado, argumentos de apoio à pluralidade na escola, combate à violência e promoção de respeito e igualdade; do outro, "Gênero não" e contra a destruição da família e ditadura comunista nas escolas. A elaboração dos planos se mostrou uma disputa, mesmo já tendo vencedores estabelecidos previamente.

Ao contrário da produção dos PEs, a Reforma do Ensino Médio se deu por meio de Medida Provisória-MP 746/2016, transformada em Lei Ordinária 13.415 (BRASIL, 2017). A MP deu à reforma critério de urgência, ação que facilita o rito, acelera o tempo e centraliza os debates. A aceleração do tempo é também o atropelo da democracia nos ritos de produção curriculares, pois se ouve menos gente e se aprova mais rapidamente.

Seja o rito realizado rapidamente, ou com trâmites mais espaçados, ele ocorre e tem por objetivo firmar cinicamente que foi produzido democraticamente, de modo a ser um desejo social e, portanto, acatado por todos. Ninguém pode negar-se ao cumprimento dessa lei, pois estaria traindo os desejos da sociedade. A Santíssima Trindade do executivo, legislativo e judiciário, que institui o regime disciplinar do vigiar e punir, é a mesma que descumpre a lei, instaurando uma sociedade de vigilância (FOUCAULT, 2014). Aquele que infringe a lei, infringe também a verdade e o direito.

\footnotetext{
4 Trata-se neofundamentalista, como aquele que não se importa "verdadeiramente com a verdade", mas sim de um acordo prévio com a ignorância, elevada a método de dominação cultural, agindo desonestamente e não importando se acredita ou não na verdade que prega. $O$ interesse do neofundamentalista são os efeitos e seu resultado: voto, dinheiro, audiência (TIBURI, 2016).
} 
Ora, o dever e o direito sustentam a falsa ideia de livre arbítrio, autorizando nosso direito sobre os outros e o direito dos outros sobre nós. Assim, se violam nosso direito, violam a verdade e os costumes, perturbam a ordem; dessa forma estamos autorizados ao justiçamento, para manter a ordem (NIETZSCHE, s/d/).

Nesse tocante, o currículo se instaura como costume, mantendo regulamentações penosas, estabelecendo-se como regras. Regras de normalização e individuação. Individuação realizada por técnicas de poder, que transmitem as responsabilidades de si e dos outros ao indivíduo, e a normalização, que se encontra alinhada à produção dos sujeitos e agenciamento de subjetividades, de modo que esses devem encontrar-se de acordo com as normas sociais, as leis que regimentam seus corpos, de acordo com o saber-poder-verdade eleito (FOUCAULT, 2015; 2014a; 2014b; BRANCO, 2015).

Dessa forma, o estabelecimento de metas pelo Plano de Educação e de estrutura de ensino pela MP 746/2016 planeja o que é a verdade a ser ensinada e em quais moldes deverá ser. Esse planejamento explica como ele será executado, como esses saberes formativos serão veiculados na escola. A avaliação, a terceira técnica essencial para validar, se sucumbiu à verdade dos sujeitos que se tornarem seus portadores (VEIGA-NETO, 2012).

Vemos aqui a avaliação como uma etapa essencial no processo de controle de qualidade da escola, visto que é nela que o estudante dá seu testemunho, sua confissão sobre a verdade. Se ele foi aprovado no ano letivo, ele deve ter adquirido saberes formativos daquela série e, assim, tem aquela verdade em mente. É como quem assina a ata após o júri, a confissão foi tomada e se tornou um fato de que ele deve saber. Se, em algum momento futuro, ele errar, é uma responsabilidade individual; se errar na avaliação, não é aprovado como detentor de saberes formativos. O currículo assim é a instituição de regras e normas, que devem ser seguidas e jamais quebradas, para que o estudante alcance a verdade que regulará sua vida individual e coletiva.

Mas, e os Sereianos?

Os Sereianos aqui são as criaturas míticas, que se colocarão como os guardiões das regras. Harry conhecia as regras, levar apenas uma pessoa, 
mas a quebrou, sendo então atacado por centenas de Sereianos, que buscavam mantê-lo submerso, podendo até mesmo matá-lo afogado. Os Sereianos seriam então o policiamento, a vigília, o que vigia e pune. Sob o viés da sociedade disciplinar, todos exercem o policiamento, vigiando e punindo $o$ outro por meios de métodos de vigilância (FOUCAULT, 2014). Figuras míticas a ponto de transcender os humanos com tecnologias de seguridade (BRANCO, 2015), utilizando câmeras, monitoramento das redes sociais, acompanhamento de notas e desempenho, entre outras, por meio de tecnologias de seguridade (BRANCO, 2015). Não é apenas o outro que exerce a vigília, mas também o próprio sujeito (Ó, 2010). É a junção de métodos disciplinares e tecnologias de seguridade, bem como o dispositivo da seguridade social, que institui a sociedade de controle (BRANCO, 2015).

A obediência às regras e aos costumes é o que Nietzsche $(\mathrm{s} / \mathrm{d} /$ ) chama de moralidade, mecanismos regulatórios que modulam 0 agir e 0 avaliar pautando-se em uma verdade. Esse policiamento é então um policiamento moral, visto que segue preceitos metafísicos (o currículo) de verdadeiro ou falso e manutenção do status quo.

Os Sereianos, a milícia da moralidade, atuam no currículo desde sua produção, na seleção dos grupos de elaboração, elegendo quais conteúdos e disciplinas serão acolhidos, os termos que serão apagados e barganhados, quem estará presente no dia da votação... Como serão contratados os professores, o planejamento para dar conta de todo o conteúdo, como ele deve agir para melhores resultados, como vai avaliar... Como esse professor será vigiado, quais registros precisará fazer, o que deve prestar conta, os prazos... Quais alunos terão acesso à escola, quais serão mantidos, os comportamentos ideais, as notas de corte... A rede é de vigília contínua, no qual todos se vigiam em nome do totem saber formativo-poder-verdade.

Se algum tentar escapar às regras curriculares, será - como Harry atacado por milhares de Sereianos; alguns podem escapar do ataque, outros não. Os novos movimentos sociais neofundamentalistas, como "Cristãos pela Família", "Pais contra a ideologia de gênero", "Movimento Escola Sem Partido" têm se envolvido em barganhas com o legislativo para a construção de novos currículos (como se viu nas votações dos Planos de Educação). Eles têm medo 
de que as regras de suas produções não sejam seguidas à risca e sua estratégia é estabelecer uma nova política de vigilância: a política da delação.

Apesar de serem movimentos diferentes, têm pautas em comum, como, por exemplo, o estudante conhecer as regras e os deveres da instituição escolar, para que delatem qualquer sujeito que fuja a elas. A delação se torna então um sinônimo de virtude, de modo que se fará um bem não a si, mas a toda a sociedade, é um ato heroico (GADOTTI, 2016).

Os novos movimentos sociais neofundamentalistas produzem assim novos Sereianos. É a filosofia do "Herói”, um presente pelos serviços prestados de delação premiada. É com medo da delação, de ser atacado por milhares de Sereianos, que a comunidade escolar é calada sobre assuntos dados como 'contundentes', não instituídos como verdade hegemônica. Os Sereianos são assim aqueles que se renderam ao exercício de poder dos discursos eleitos como verdadeiros, que foram calados por eles, que estagnaram em uma verdade e decidiram manter-se parados. Sob as políticas de eleição de saberes verdadeiros, vigilância e, punição, seria então a escola e o currículo de ciências o espaço do calar?

\section{Ulisses: o silêncio das sereias}

Há quem diga que a escola já cumpriu seu papel no que toca a veiculação de discursos eleitos como formativos e como verdade, e que essa conformação já não serve mais. A escola assim é um espaço que cala, seja por meio da milícia sereiana ou por assinar o termo de aceitação de todas as verdades por ela veiculadas.

Ressalta-se que essa escola do fazer calar não representa as bases filosóficas da educação-escola, voltada à ocupação do tempo comum, da coletividade, da criatividade, da troca, das relações democratizadas - nessa, as vozes ecoam, e o silêncio é criação (MASSCHLEIN; SIMONS, 2014). A escola que situamos aqui é aquela atravessada pelas linhas do neoliberalismo e neofundamentalismo, que operam pedagogias dos corpos voltadas a uma formação para o individualismo, competitividade, moralismos, utilitarismo dos saberes e pelo desejo miliciano de dominar e converter o outro. 
Nesse âmago, convido outras sereias para compor esta reflexão, não as do calar, mas as que se silenciam como forma de resistência 5 .

Para isso, retomo a cena 2.

Ulisses, o herói e desbravador, que parte em aventuras em busca de novas terras para colonizar e levar suas verdades, quer escutar o canto das sereias sem se render a elas; equipa-se para não ser derrotado, mas elas se silenciam-se. Ele finge que ouviu, mas elas não cantaram. É assim que arrastamos ao centro deste manuscrito, não Ulisses, mas seu barco, as Sereias e o silêncio.

Ulisses pode ser um ícone de heroísmo em suas cruzadas e desbravações, contanto que seu barco seja um marco. O barco de Ulisses, como sabemos, é feito de madeira, que, por mais tratada que seja, após inúmeras viagens, precisa ser reparada, tratada e trocada. O barco não é todo modificado em uma única viagem, mas, a cada viagem que coloca o barco ao mar, algo é modificado nele. Assim, a cada viagem que carrega sua verdade, o barco não retorna igual. Desse modo, para levar o herói e suas verdades, o barco é constantemente modificado.

O barco que carrega as verdades seria nosso currículo. Se os primeiros currículos que surgem no pós-Revolução Industrial fossem analisados e comparados seus efeitos e discursividades até os atuais, veríamos que suas peças foram aos poucos trocadas (SILVA, 2015). O currículo não é o mesmo, seus efeitos não são os mesmos, mas seu propósito é similar: eleger verdades, regular corpos e mentes e o governo de si e dos outros. Esse governo, baseado em sua verdade instituída, tem o domínio do poder-calar.

Contudo, temos inspirações e devaneios, quando vemos Larrosa (2001) diferenciar o calar e o silêncio. Para ele, o calar é a incapacidade da palavra, são as rotinas da linguagem, a delimitação de fronteiras, é a retirada da vida, a

\footnotetext{
${ }^{5}$ Compreende-se, neste manuscrito, que a sereia tem uma simbolização mitológica daquele que encanta e mata e as utilizamos neste sentido - o limiar entre a liberdade de uma óptica progressista, do comum e da sua perversão pela racionalidade neoliberal é uma linha de encantamento tênue. Contudo, aqui chamamos a atenção para a necessidade do encanto enquanto uma técnica de resistência, ao passo que ela resiste aos heroísmos, aos salvacionismos, aos messianismos (geralmente associados às discursividades neoliberais), coloca-os ao julgo da crítica e os afoga quando analisados a fundo. Em síntese, vê-se uma produtividade no encanto que perturba a norma e cinde as promessas de fixismo, mas se vê um perigo no encanto neoliberal que convida os sujeitos a nadarem em águas onde encontrarão a sujeição.
} 
tentativa de purificar as coisas e retirar o ruído delas. Por outro lado, fazer silêncio é fazer aberto o mundo, as possibilidades, é contemplação, é a fresta ao estranho, ao impensável, ao amorfo, ao delineado aos sem sentidos, são as potencialidades. Se o calar tira as potencialidades, o silêncio se abre a elas.

E assim, podemos pensar as Sereias que não cantam quando Ulisses passa todo blindado. Ao verem-no, atento demais a estratégias racionais para derrotá-las, blindado à entrega de seu canto mítico e telúrico, elas silenciaram. Um silêncio de resistência. Resistentes, a ponto de não darem seu veredito, para ver se seriam derrotadas ou não pela racionalidade, a não confessar sobre o tribunal de Ulisses. É nesse sentido, que o silêncio pode ser compreendido como uma tecnologia ética de resistência, como aquele que se cala durante o interrogatório (BUTLER, 2015). Elas poderiam saber (en)cantar, ou não, mas elas se negam a isso, deixando ao júri a dúvida. Ulisses segue seu caminho, como se tivesse ouvido, essa verdade cínica será seu peso.

A exemplificar, poderíamos pensar no/a estudante que cala sua imaginação, para reproduzir as verdades ou no/a que prefere silenciar-se e deixar ao currículo a dúvida. Podemos pensar naqueles que ironizam em suas falas e escritas e, assim, abrem frestas ao silêncio. Mas podemos também pensar aos que fogem a essa fresta, aos que vazam a escola, aos que cantam em outros mares.

É nesse sentido, que Sibilia (2012) levanta considerações acerca da escola como campo formativo, que investiu séculos na constituição e normalização dos modos de ser e, contudo, à medida que os corpos mudam, que se afrouxam regras e que as verdades eleitas não sustentam mais os corpos dentro desse espaço, ele trinca, afrouxa, transborda, e suas regras são transgredidas. Os silêncios produzem essas frestas e possibilitam o vazar para outros espaços - como citado anteriormente, esses silêncios encontram lugares nas escolas democráticas (MASSCHLEIN; SIMONS, 2014), do coletivo e comum, mas não na escola neoliberalizada.

Enquanto os Sereianos eram agenciados a cercar e policiar pelas regras, as Sereias de Ulisses silenciam quando precisam e cantam em outros espaços. Não pense que apenas as Sereias de Ulisses se aproveitam das fraturas para se aventurarem em outros espaços; os Sereianos, aproveitam 
também dessas frestas para policiar em outros mares. Mas qual seriam esses outros espaços?

\section{Outros espaços e a ampliação da liberdade}

Se o saber-poder-verdade atua regulando a constituição de si e dos outros, a escola é um espaço privilegiado no que toca a veiculação de verdades eleitas e modos de vida aceitáveis, docilizando corpos e mentes. $\mathrm{O}$ que valida esse saber é a autenticidade da cientificidade no conhecimento escolar e um sistema legislativo de composição dos currículos, garantindo uma sugestiva pureza desse saber. Assim, o local de canto será no sujo. É no mundano, que se encontram as potencialidades do falar e do deslocar o que se vê e entende por verdade. É onde o som dessoa e é possível ouvir outras vozes. O silêncio pode ser encontrado nas literaturas, novelas, músicas, séries televisivas, na mesa de um bar, em viagens, paisagens. O silêncio que não é calado por uma verdade, mas para de falar para contemplar. Silêncio que não significa uma despersonificação de si, uma neutralidade, um não falar, mas, sim, uma abertura às possibilidades (LARROSA, 2001).

Dessa maneira, a escola e o currículo são vazados. Sua estrutura rígida, seu desejo por respostas objetivas e por uma racionalidade definitiva são um jogar concreto, um vedar paredes, o fechar para dúvida. Rituais de calar e não de promover silêncios (LARROSA, 2001). Se, na escola, as Sereias não cantam, são outras águas que elas buscam para cantar. É a essa busca de outros espaços que chamamos de resistência.

Para Foucault (2016; 2015; 2014a; 2014b; 2007; BRANCO, 2015), a resistência se faz onde existe o poder. A premissa para que existam relações de poder é o sujeito possuir liberdade. Ao acabar a liberdade, o que teríamos não seriam relações de poder, mas, sim, relações de tirania. Assim, a resistência é uma técnica de ampliação de liberdade.

Não é possível chegar a uma liberdade total, escapar de relações de poder, visto que existem condições que limitam a liberdade; contudo, é possível ampliá-la por meio das práticas de resistência. É a resistência que retira o sujeito da acomodação social e da fixação na normalidade. Essa resistência é um continuum, é um vir-a-ser, um devir, um trabalho de Sísifo. 
Vemos no cantar em outros espaços uma prática de resistência, que não é livre da milícia Sereiana, mas possibilita manter as verdades como problemas, não cristalizadas e não caladas, mas, sim, em potencialidades e disputas, entre ampliação e redução das liberdades. É assim que vemos as redes sociais como potencial ampliador de liberdades. Como espaços nos quais as Sereias podem cantar e os Sereianos policiar.

É nesse ponto que, se queremos compreender as tecnologias de poder, de si e a ampliação da liberdade, um dos instrumentais é, segundo Foucault (2016; 2015; 2014; BRANCO, 2015), o diagnóstico do presente. Se quisermos saber onde e como as Sereias estão cantando, já que não cantam (ou não tanto) na escola (neoliberal), devemos investigar esses outros espaços. Se quisermos compreender como os currículos ainda influenciam os corpos dos sujeitos, devemos investigar esses outros espaços - que atravessam os espaços escolares. Se quisermos entender como os movimentos sociais minoritários e os movimentos sociais neofundamentalistas têm agenciado os jovens, devemos investigar (também) outros espaços... ${ }^{6}$

\section{As redes sociais como um espaço outro}

Os espaços que podemos escutar (também) o canto das sereias são os mais diversos: parques, praças, fábricas, comércios, Internet, prédios públicos, enfim... Contudo, a Internet e as redes sociais têm nos instigado no que toca o ouvir as Sereias. O que me leva a pensar nisso, senão: a) as modificações no campo cultural e a instituição da cibercultura e b) a fuga das milícias de Sereianos.

O surgir da Internet e das redes sociais possibilitou uma modificação significativa nos modos de pensar cultura. A Internet rompe fronteiras do espaço e do tempo, coloca em contato pessoas imersas em regionalidades e

\footnotetext{
${ }^{6}$ Não buscamos, neste manuscrito, criar o ideário de que a escola esgotada de seu potencial criativo, transformativo e de elaborações, e as redes sociais são um espaço de produção pura; essa posição seria não apenas falaciosa, como jogaria água no moinho do neoliberalismo, que reina no ciberespaço. O que pontuamos aqui e convidamos o olhar é a atenção para as capturas neoliberais do espaço escolar - que fazem calar - e, como os outros espaços, têm produzido dinâmicas pedagógicas e reivindicações que atravessam o espaço-escola. Faz-se o adendo para que não aparente que, neste texto, realizamos um culto ao ciberespaço e uma crítica à escola; o que buscamos é um convite a pensar ambos os espaços - a considerar que que se faz urgente uma defesa da escola para a formação crítica dos sujeitos (MASSCHLEIN; SIMONS, 2014).
} 
tradições distintas. As hibridizações culturais se intensificam com ela, bem como a ideia de registro. O real e o virtual passam a se hibridizar, tornando-se indissociáveis. O rompimento de fronteiras abre espaços para a exploração de potencialidades, e o próprio significado de texto é revisto, visto que a interconexão de mensagens abre espaço para múltiplos sentidos e representações (LÉVY, 1999).

Como Lévy (1999), pensamos que a cibercultura coloca em xeque a ideia de significado estático. Se o significado não é mais estático, ele é continuamente renovado, revisitado, revisado, retraduzido, transbordado. Se a quantidade de verdades arquivadas, os significados e as interpretações se contradizem, no que se deve acreditar? Nesse anseio do excesso de informações e de dúvidas, os saberes cristalizados passam a se esfacelar. A cibercultura não fica apenas nas redes digitais, ela também regula e interfere nos modos de ser, agir e pensar. Mas os currículos fechados em planejamento, ação e avaliação (VEIGA-NETO, 2012) estariam preparados para nutrir e incitar as dúvidas e potências?

Apesar de as ciberculturas abrirem espaço para exploração das potências, não se pode cair na falácia do livre espaço. Na Internet e nas redes sociais, as milícias também atuam. As intimidações presenciais são transportadas ao (cyber)espaço e atuam tão intensamente quanto nos espaços físicos (FREIRE et al., 2013). A própria ideia da Internet como espaço sem lei faz com que ataques e ameaças se tornem mais intensos e frequentes. Assim, as redesse mantêm como espaço de vigilância e controle.

No entanto, com novas possibilidades de relação e de expressão, os regimes de verdade que precarizam os corpos, as identidades e as diferenças, agora são trincadas pela Internet, as regras; e as moralidades e os saberes dados como válidos, agora se encontram fragmentados, se não diluídosdifusos e flutuando nas redes (PRADAS, 2006). É nesse espaço virtual e com outras técnicas e possibilidades de manifestação e expressão, que, apesar das violências e dos Sereianos, possibilita-se a produção de novas subjetividades, novas lentes para ler o mundo, novos espelhos para se ver e ver o outro (ROSA, 2011). É o espaço onde as Sereias podem cantar seus cantos telúricos 
ou silenciar. Espaço onde os Sereianos podem tentar calar, mas encontrarão resistências mais bem equipadas-articuladas ${ }^{7}$.

Entretanto, há nesse ciberespaço, dinâmicas de articulação tão intensas que os encantos neoliberais hibridizam Sereias e Sereianos, passam a atuar nesses espaços Sereias-Sereianos, que operam cantos de encantamento neoliberal e policiamento virtual. Quando tal hibridização opera, perde-se o potencial criativo e crítico dos cantos das Sereias, que deixam de encantar para produzir linhas de fuga dos espaços-saberes cristalizados - fugas que produzem diversidades - e passam a encantar para convidar à operação em racionalidades neoliberais. São os encantamentos neoliberais que convidam ao assujeitamento voluntário, re-fixam regimes de verdades e policiam quem tenta escapar desse regime de racionalidade (neoliberal).

Reiteramos com isso, que reconhecemos a potencialidade das redes para ouvir os cantos das Sereias, vislumbrar o que vaza à escola e onde é possível ver os que tinham suas culturas negadas (SANTOMÉ, 2013). Entretanto, deve-se ter cuidado com a ideia de Internet como espaço onde todos os ruídos podem ser ouvidos e todo canto mítico escutado. Deve-se ter cuidado, pois as redes tentam fazer conosco o que Ulisses fez com sua tripulação: utilizar de estratégias racionais para o blindar dos cantos das sereias.

O próprio Facebook ${ }^{8}$ relaciona as postagens que aparecerão no perfil do usuário, de acordo com o que ele curte, denuncia e visita cotidianamente. Se formos utilizar as redes sociais para ouvir o canto das Sereias, temos que ter cautela para não cairmos em uma análise muda, calada, pelos instrumentais da própria rede.

\section{Considerações}

Instigamos: Seriam então as redes novos currículos? São artefatos culturais que modulam os modos de ser e estar no mundo. Ambos produzem

\footnotetext{
7 É necessário ressaltar que o ciberespaço não substitui a escola, mas é um espaço outro dentro do próprio espaço escolar. É a isso que chamamos atenção neste texto, a necessidade de voltar o olhar para as fraturas, trincos e duplicações espaço-temporais que vazam a escola e, ao mesmo tempo, se conectam a estas (SIBILIA, 2012).

8 Consiste em uma rede social digital,, fundada no ano de 2004 amplamente difundida e utilizada.
} 
formas de subjetividade relacionados a tração saber-poder-verdade. Qual seria então a diferença entre ambos?

Vemos que o currículo escolar tem a preocupação com a verdade, em cristalizá-la, em torná-la formativa. Tais indícios mostram a necessidade de deslocar a verdade de seu estatuto para pensar em termos de saberes, validados por diferentes modos de veridicção e elaborado-dialogado em conjuntos (dentro e fora dos espaços escolares). Essa torção que se faz urgente para elaborar novas possibilidades de escuta é essencial para devolver à escola seu potencial democrático-criativo - retirá-la das bases neoliberais.

Enquanto isso, as redes não estão preocupadas com uma única verdade, são as redes que mantêm a verdade sob o olhar da dúvida, dos embates, das incertezas, das controvérsias. Há, portanto, o ecoar de vozes, que devem também ser percebidas com atenção e cuidado, para que, com isso, não se perca a demanda de modos de validação-legitimação de saberes e se recaia em um território da pós-verdade operante. É o ciberespaço um campo potencial para fazer cantar - bem como a escola democrático-criativa; contudo, há também os gritos ensurdecedores que também podem esvaziar o potencial criativo cibercultural.

Evidencia-se, nesse sentido, que são nas redes que Sereias não autorizadas (excluídas, segregadas ou negadas) a cantar no espaço escolar neoliberal passam a cantar. É nas redes, que o fluxo se intensifica, que se desterritorializa, que vaza, que permite os conflitos, que mantém as verdades em xeque, que permite uma reconexão com a escola - seja para amplificar o fazer-calar, ou para multiplicar as vozes cantadas.

Ressalta-se que nosso intuito neste ensaio não é esgotar a escola e desenvolver uma apologia ao ciberespaço. O que gostaríamos aqui é de colocar a escola neoliberal que faz calar em crítica; convidar a pensar outros espaços em que os eliminados, excluídos e segregados (da escola neoliberal) passam a ecoar suas vozes; traçar problemáticas de que pedagogias se criam a partir desses outros usos dos espaços e de seus cantos - e como esses tocam o espaço escolar; e, por fim, manter sob o julgo da crítica a ideia do ciberespaço-cibercultura como um local de liberdade pura, criação pura e desterritorialização pura, aponto que tal espaço é, também, um espaço de regulação, controle e milícias. 
É dessa perspectiva que não temos como intenção fechar este trabalho, trazer respostas ou firmar o que deve ser feito. Pelo contrário, queremos colocar as verdades em jogo, inquietar-se, mobilizar as certezas. Se este texto parece harmonioso, consonante e o leitor, ao seu fim, concorda com ele todo, sugerimos uma releitura ou dispensá-lo. Se soa dissidente, gera inquietação e vontade de resposta e continuidade, acreditamos no alcance de nosso objetivo e pedimos que mantenha a esperança em continuá-lo.

É esta nossa intenção com este trabalho: proporcionar a golpes de martelo, uma abertura, fissuras e novas possibilidades.

\section{Referências bibliográficas}

ARROYO, Miguel G. Os movimentos sociais e a construção de outros currículos. Educar em revista, Curitiba, n. 35, p. 47-68, 2015.

BRANCO, Guilherme Castelo. Michel Foucault: filosofia e biopolítica. Belo Horizonte: Autêntica, 2015.

BRASIL. Constituição da República Federativa do Brasil. Brasília: Senado Federal, 1988.

BRASIL. Lei de Diretrizes e Bases da Educação Nacional - Lei ํo 9.394 de 20 de dezembro de 1996. Brasília-DF: Presidência da República, 1996.

BRASIL. Lei no 13.145 de 16 de fevereiro de 2017. Brasília-DF: Presidência da República, 2017.

BUTLER, Judith. Relatar a si mesmo: crítica da violência ética. Belo Horizonte: Autêntica, 2015.

CARVALHO, Fabiana Aparecida de et al. Políticas públicas e (in)visibilidades escolares: entre (des)conhecer, apagar e trabalhar com o combate à violência de gênero. In: CORREA, Crishna Mirella de Andrade; MAIO, Eliane Rose (Orgs.). Observatório de violência de gênero: entre políticas públicas e práticas pedagógicas. Curitiba: CRV, 2015. p. 99-114

FAVACHO, André Marcio Picanço. Currículo, subjetivação e experiência de si: contra os humanismos, os modismos e os relatos obtusos. Currículo sem fronteira, Rio de Janeiro, v. 16, n. 1, p. 488-508, 2016.

FOUCAULT, Michel. A microfísica do poder. 4. ed. Rio de Janeiro:

Paz\&Terra, 2016.

FOUCAULT, Michel. As palavras e as coisas: uma arqueologia das ciências humanas. São Paulo: Martins Fontes, 2007.

FOUCAULT, Michel. História da sexualidade: a vontade de saber. 3. ed. São Paulo: Paz\&Terra, 2015.

FOUCAULT, Michel. Vigiar e punir. 42. ed. Petrópolis: 2014a

FOUCAULT, Michel. A ordem do discurso: aula inaugural no Collège de France, pronunciada em 2 de dezembro de 1970. 24. ed. São Paulo: Editora Loyola, 2014b. 
FREIRE, Isabel et al. Cyberbullying e ambiente escolar: um estudo exploratório e colaborativo entre a escola e a universidade. Revista portuguesa de pedagogia, Coimbra, n. 47, v.2, p. 43-64, 2013.

GADOTTI, Moacir. A escola cidadã frente ao "Escola sem Partido". In: AÇÃO EDUCATIVA (Org.). A ideologia do movimento Escola sem Partido: 20 autores desmontam o discurso. São Paulo: Ação Educativa, 2016. p. 149-160. GOODSON, Ivor F. Currículo: teoria e história. 8. ed. Petrópolis: Vozes, 2008. HARRY POTTER: e o cálice de fogo. Produção de Mike Newell, Londres: Heyday Films, 2005. filme digital. 157 min.

LARROSA, Jorge. Pedagogia profana: danças, piruetas e mascaradas. 4 ed. Belo Horizonte: Autêntica, 2001.

LEVY, Pierre. Cibercultura. São Paulo: Editora 34, 1999.

MASSCHELEIN, Jan; SIMONS, Maarten. Em defesa da escola: uma questão pública. 2 ed. Belo Horizonte: Autêntica, 2014.

NELSON, Cary; TREICHLER, Paula A.; GROSSBERG, Lawrence. Estudos culturais: uma introdução. In: SILVA, Tomaz Tadeu da (Org.). Alienígenas na sala de aula: uma introdução aos estudos culturais em educação. 11. ed. Petrópolis: Vozes, 2013. p. 7-37.

NIETZSCHE, Friederich. Aurora. São Paulo: Escala, s/d.

Ó, Jorge Ramos do. Para uma crítica das artes da existência e da ideia de consciência na modernidade: a problematização foucaultiana. In: VICENTINI, Paula Perin; ABRAHÃO, Maria Helena Menna Barreto (Orgs.). Sentidos, potencialidades e usos da (auto)biografia. São Paulo: Cultura Acadêmica, 2010. p. 19-48.

POLIZEL, Alexandre Luiz; CARVALHO, Fabiana Aparecida. Um currículo que violenta: invisibilidades e reações pós apagamento. In: CONGRESSO INTERNACIONAL DO NÚCLEO DE ESTUDOS DE GÊNERO E DIREITO (NEG) E DO NÚCLEO DE POLÍTICA CRIMINAL (NUPOC), 1., Maringá, 2016. Anais... Maringá: Universidade Estadual de Maringá, 2016. p. 83-92.

PRADOS, Maria Angeles Hernandez. Menores y riesgos en la Red - Un dilema para los padres. In: CONGRESO ON LINE- OBSERVATORIO PARA LA CIBERSOCIEDAD. 3., 2006. Anais... on-line, 2006.

ROSA, Nara Beatriz Kreling da. O uso da internet como espaço terapêutico.

Cadernos do Aplicação, Porto Alegre, n. 24, v.2, p.131-143, 2011.

SANTOMÉ, Furjo Torres. As culturas negadas e silenciadas nos currículos. In: SILVA, Tomaz Tadeu da. (Orgs.). Alienígena na sala de aula: uma introdução aos estudos culturais em educação. 11. ed. Petrópolis: Editora Vozes, 2013. p. 155-172.

SIBILIA, Paula. Redes ou paredes: a escola em tempos de dispersão. Rio de Janeiro: Contraponto, 2012

SILVA, Tomaz Tadeu da. Documentos de identidade: uma introdução às terias do currículo. 3. ed. Belo Horizonte: Autêntica Editora, 2015.

SILVA, Tomaz Tadeu da. O currículo como fetiche: a poética e a política do texto curricular. 2. ed. Belo Horizonte: Autêntica, 2001.

TIBURI, Marcia. Como conversar com um fascista: reflexões sobre o cotidiano autoritário brasileiro. 5. ed. Rio de Janeiro: Record, 2016.

VEIGA-NETO, Alfredo. Currículo: um desvio a direita ou delírios avaliatórios? In: COLÓQUIO DE QUESTÕES CURRICULARES E VI COLÓQUIO LUSOBRASILEIRO DE CURRÍCULO, 20., Campinas, 2012. Anais... Campinas: Universidade Estadual de Campinas, 2012. p. 1-17. 
YAZBEK, André Constantino. 10 lições sobre Foucault. 6. ed. Petrópolis: Vozes, 2015. 